\title{
KELAYAKAN LAHAN PERTAMBAKAN DI TANAH SULFAT MASAM, KABUPATEN LUWU TIMUR, SULAWESI SELATAN
}

\author{
Brata Pantjara*), Aliman*), Abdul Mansyur*), dan Utojo*)
}

\begin{abstract}
ABSTRAK
Salah satu lahan yang bisa dikembangkan untuk budi daya tambak adalah tanah sulfat masam. Di Indonesia potensinya cukup luas dan umumnya lahan semacam ini berada di kawasan pesisir. Penelitian ini bertujuan untuk mengetahui potensi kelayakan lahan tanah sulfat masam untuk pertambakan dan optimalisasi pemanfaatannya berdasarkan tingkat kesesuaian lahan dan daya dukung lingkungan. Penelitian dilakukan di Kabupaten Luwu Timur, Sulawesi Selatan. Metode penelitian dengan melakukan survai untuk mendapatkan data primer. Sedangkan data sekunder diperoleh dari instansi terkait dan peta yang diperlukan untuk proses analisis dengan Sistem Informasi Geografis (SIG). Analisis data melalui tumpang susun dari beberapa peta dan data primer pada setiap pengamatan dengan mempertimbangkan pembobotan dan skala penilaian untuk mendapatkan nilai skoring dalam menentukan kesesuaian lahan budi daya tambak. Hasil analisis kelayakan lahan untuk tambak didapatkan nilai potensi dan kelayakan seluas $5.617,9$ ha yang terdiri atas 709,4 ha kelayakan tinggi; $3.947,7$ ha kelayakan sedang; dan 960,7 ha kelayakan rendah.
\end{abstract}

\section{ABSTRACT: Suitable land for brackish water aquaculture in acid sulfate soil at East Luwu Regency, South Sulawesi. By: Brata Pantjara, Aliman, A. Mansyur, and Utojo}

\begin{abstract}
One of land that can be developed for brackish water aquaculture is acid sulfate soil. The potency of acid sulfate soil in Indonesia is relatively large and generally found in coastal area. The objectives of this research to know the potency and land suitability of acid sulfate soil for brackish water aquaculture and optimal utilization based on land suitability level and its carrying capacity. This research was conducted at Malili Sub District; East Luwu Regency, South Sulawesi. Surveys have been done collected primary data. while secondary data was obtained from related Institution and needed maps for Geographic Information System (GIS) analysis, with overlying maps and primary data in each station observation with considering and assessment scale value of determining land suitability for brackish water pond. The result of maps analysis had been obtained the potency and land suitability at Malili Sub district were 5,617.9 ha consisted of 709.4 ha (high suitability); 3,947.7 ha (moderate suitability); and 960.7 ha (low suitability).
\end{abstract}

\section{KEYWORDS: land suitability, maps, brackish water, acid sulfate soil}

\section{PENDAHULUAN}

Pembukaan lahan baru untuk pengembangan tambak dewasa ini sangat rentan terhadap kerusakan. Hal ini terjadi karena tidak ada keseimbangan antara daya dukung lingkungan dengan lahan untuk budi daya. Pembukaan lahan marginal menjadi tambak kurang termanfaatkan secara optimal karena pembudi daya tambak tidak mengetahui karakteristik tanahnya. Apabila fenomena ini dibiarkan terus- menerus, maka lahan marginal seperti tanah sulfat masam yang banyak dijumpai di kawasan pesisir dan dibangun untuk areal pertambakan semakin luas dan menjadi lahan terlantar.

*) Peneliti pada Balai Riset Perikanan Budidaya Air Payau, Maros 
Menurut Bengen $\left(2004^{a}\right)$, salah satu degradasi sumber daya pesisir yang cukup menonjol adalah degradasi hutan mangrove sebagai akibat pembukaan lahan atau konversi hutan mangrove menjadi pertambakan. Kondisi yang sama juga terdapat di Kabupaten Luwu Timur, Sulawesi Selatan, yang umumnya hutan mangrove tersebar hampir di kawasan pesisir dan sebagian besar telah dikonversi menjadi areal pertambakan. Jenis tanah di kawasan mangrove ini didominasi oleh tanah sulfat masam yang berasosiasi dengan gambut. Mengingat keberadaan hutan mangrove mempunyai peranan yang cukup besar dan penting tidak hanya untuk industri kayu tetapi juga sebagai penahan gelombang laut agar tidak terjadi abrasi pantai (Boran et al., 1998). Bagi perikanan keberadaan mangrove sangat penting karena berfungsi sebagai penyangga tambak dan daerah asuhan ikan (nursery ground) dan menciptakan iklim mikro serta fungsi lainnya.

Dalam rangka mengatur pengelolaan tambak tanah sulfat masam yang produktivitas tanahnya tergolong rendah, maka diperlukan pengelolaan yang baik sehingga tambaknya dapat berdaya guna sesuai dengan daya dukung tambak di tanah sulfat masam. Penataan kembali model tambak berwawasan lingkungan dan berkelanjutan dengan menghijaukan kembali sebagian mangrove yang sudah rusak perlu dilakukan. Menurut Poernomo (1992), penerapan tambak udang yang baik adalah dengan mengutamakan keterpaduan pengelolaan tambak dengan lingkungan. Kegagalan tambak udang berhubungan dengan banyak faktor antara lain tata ruang tambak yang tidak baik dan kurangnya pemahaman terhadap lingkungan serta teknologi budi daya. Selain itu juga disebabkan degradasi lingkungan dan lemahnya pengelolaan dalam berbudi daya.

Untuk mengatasi masalah tersebut diperlukan data dan informasi mengenai sumber daya lahan khususnya untuk tambak di kawasan pesisir. Informasi ini sangat penting dalam mendukung program pembangunan suatu wilayah khususnya di sektor perikanan di Kabupaten Luwu Timur. Data dan informasi mengenai sumber daya lahan dapat diperoleh dengan melakukan kegiatan penelitian dengan metode survai dan pemetaan tanah dengan metode sistem informasi geografis.

Penelitian ini bertujuan untuk mengetahui potensi kelayakan tambak dan optimalisasi pemanfaatan ruang berdasarkan kesesuaian lahan dan daya dukung lingkungan tambak tanah sulfat masam Kecamatan Malili, Kabupaten Luwu Timur, Sulawesi Selatan. Hasil penelitian ini diharapkan menjadi bahan pertimbangan bagi pemerintah daerah dalam menyusun pola kebijakan dalam pengembangan perikanan.

\section{METODE PENELITIAN}

Penyusunan tata ruang dilakukan dengan memperhatikan keragaman kawasan lahan budi daya yang disurvai (McRae \& Burnham, 1981). Data dan informasi diperoleh dengan mengumpulkan beberapa parameter kesesuaian lahan tambak, data tersebut selanjutnya digunakan sebagai dasar mentabulasi data dalam rangka mengevaluasi tata ruang dan menetapkan sistem teknologi budi daya yang dapat dikembangkan dalam pengambilan keputusan.

Survai dilakukan di Kecamatan Malili, Kabupaten Luwu Timur, Sulawesi Selatan. Data sekunder diperoleh dari Dinas Kelautan dan Perikanan Kabupaten Luwu Timur, Sulawesi Selatan. Pilihan lokasi berdasarkan tata ruang wilayah untuk pengembangan budi daya tambak. Data iklim diperoleh dari Badan Meteorologi dan Geofisika Kabupaten Luwu Timur. Peta citra dan peta rupabumi yang digunakan bersumber dari LAPAN dan Bakosurtanal tahun 1992, peta tekstur dan $\mathrm{pH}$ tanah diperoleh dari hasil pengukuran lapangan. Sedangkan peta garis pantai, penutupan areal, dan kelerengan lahan diperoleh dari Badan Pertanahan Nasional. Peta- peta tersebut digunakan sebagai peta kerja di lapangan. Data primer seperti kualitas tanah dan air diperoleh dari hasil analisis laboratorium. Titik pengambilan sampel di lapangan berdasarkan metode transek dengan menentukan titik-titik pengamatan yang dianggap mewakili daerah yang disurvai berdasarkan kondisi lahan dan tingkat kehomogenitasan Iahan (Duivenbooden, 1995). Posisi pengambilan sampel tanah ditentukan koordinatnya dengan menggunakan alat Global Positioning System (GPS). Data dan informasi yang dihasilkan merupakan data dasar untuk menyusun peta kesesuaian Iahan dan tata ruang untuk budi daya tambak (Gunawan, 1998; Nath et al., 2000).

Parameter utama yang diamati untuk kelayakan lahan budi daya tambak tanah sulfat masam meliputi topografi pantai dan dasar 
perairan, jarak dari sungai, jarak dari pantai, tekstur tanah, $\mathrm{pH}$ yang diukur langsung di lapangan ( $\mathrm{pHF}), \mathrm{pH}$ yang dioksidasi dengan $\mathrm{H}_{2} \mathrm{O}_{2}$ (pHFOX), untuk mengetahui tanah sulfat masam dalam keadaan tereduksi atau tanah sulfat masam potensial diketahui dengan Total Potencial Acidity (TPA), dan tanah sulfat masam dalam keadaan teroksidasi atau tanah sulfat masam aktual diketahui dengan Total Actual Acidity (TAA), sedangkan kemasaman berdasarkan sulfur diketahui dengan Total Sulfidic Acidity (TSA), Fe, Al, pirit (Melville, 1993), perbedaan pasang surut, keberadaan sungai hidup/sumber air tawar. Kualitas air yang diamati meliputi $\mathrm{pH}$, suhu, salinitas, logam berat, $\mathrm{DO}, \mathrm{SO}_{4}, \mathrm{NO}_{2}-\mathrm{N}, \mathrm{NO}_{3}-\mathrm{N}, \mathrm{PO}_{4}-\mathrm{P}, \mathrm{BOT}$ (APHA, 1998). Selain itu juga diperlukan data dan informasi mengenai kemudahan mendapatkan air laut, kemudahan mendapatkan air tawar, frekuensi banjir, curah hujan, adanya jalur hijau dan saluran irigasi. Faktor penunjang yang diamati meliputi ketersediaan jalan hingga lokasi, listrik, tenaga kerja, kemudahan memperoleh sarana produksi tambak, keamanan, dan pasar. Peubah tersebut selanjutnya digunakan sebagai dasar dalam menentukan skoring pada kelayakan budi daya tambak (udang windu, bandeng, dan rumput laut). Pada proses analisis peta dengan GIS menggunakan soft ware Er Mapper dan ArcView dengan memasukkan data survai dalam peta dasar melalui overlay (tumpang susun) pada setiap pengamatan dengan mempertimbangkan pembobotan dan skala penilaian untuk mendapatkan nilai kelayakan (tinggi, sedang, dan rendah) dalam menentukan kesesuaian lahan budi daya tambak, dan akan diperoleh peta yang sesuai bagi peruntukan budi daya tambak.

\section{HASIL DAN BAHASAN}

\section{Keadaan Wilayah}

Potensi tambak di Kecamatan Malili mencapai luasan 2.219 ha (Anonimous, 2003). Topografi wilayahnya bervariasi dari topografi agak datar hingga sedikit berbukit. Daerah berbukit sebagian besar dijumpai di kawasan yang menuju arah daratan. Gambaran umum pada daerah yang disurvai kemungkinan telah mengalami sedimentasi yang cukup lama berasal dari bahan- bahan mineral yang tererosi dan terangkut melalui sungai yang ada di sekitarnya ke muara, akan tetapi di muara tertahan oleh gelombang pasang surut, sehingga pengangkutan sedimen diendapkan pada daerah pantai dan sebagian terikut melalui saluran. Pengendapan sedimen tersebut juga dimungkinkan karena tumbuhan mangrove di sepanjang pantai dapat meredam energi gelombang pasang, pada perkembangan selanjutnya endapan sedimen ini akan terakumulasi membentuk suatu lapisan seperti tanah asli.

\section{Vegetasi}

Kondisi tanah tambak di kawasan ini relatif homogen, hal ini terlihat pada vegetasi yang tumbuh dan sisa vegetasi yang masih tertinggal di dalam tambak. Tambak di lahan ini umumnya ditumbuhi oleh hutan mangrove. Menurut Mustafa et al. (1994), hutan mangrove yang tumbuh di Delta Tampina, Malili terdiri atas 10 spesies yang tergolong dalam 7 genera dan 5 famili. Lokasi yang disurvai pada umumnya mempunyai karakteristik lahan yang homogen dan vegetasi mangrove yang tumbuh juga relatif sama yang didominasi oleh Rhizophorasp. (R. apiculata dan R. mucronata) dan Bruguiera sp. (B. gymnororrhiza dan $B$. parviflora) dan sebagian dari vegetasi nipah (Nypa fruticans Thunb.), Lumnitzera littorea serta paku laut. Vegetasi yang tumbuh di lokasi ini diduga dipengaruhi oleh karakteristik tanah dan pengaruh salinitas serta kurang pengaruh gelombang laut. Menurut Bengen $\left(2004^{\mathrm{b}}\right)$, karakteristik habitat hutan mangrove umumnya tumbuh pada daerah intertidal yang jenis tanahnya berlumpur, berlempung atau berpasir, menerima pasokan air tawar yang cukup atau mendapatkan air bersalinitas payau (2-22 permil) hingga asin (mencapai 38 permil), dan terlindung dari gelombang besar dan arus pasang surut yang kuat.

Pada umumnya keberadaan tanah sulfat masam di lokasi ini berasosiasi dengan tanah gambut. Beberapa pakar ilmu tanah juga menyebutkan, bahwa tanah gambut yang ditumbuhi vegetasi akan mudah berkembang menjadi tanah sulfat masam terutama di bawah vegetasi Rhizophorasp. Di lokasi ini dijumpai gundukan tanah dari kepiting Thalassina anomala.

\section{Tanah}

Lokasi tambak yang disurvai rata- rata mempunyai produktivitas yang rendah karena berbagai permasalahan terutama potensi kemasaman. Dari hasil survai di lahan potensial untuk tambak Kecamatan Malili dapat diketahui nilai rata- rata dan kisaran beberapa variabel penting tanah tambak pada beberapa titik yang 
mewakili. Nilai $\mathrm{pH}_{\mathrm{F}}$ berada pada kategori masam hingga netral, demikian pula $\mathrm{pH}_{\mathrm{Fox}}$ menunjukkan nilai tingkat kemasaman yang tinggi yang merupakan salah satu ciri tanah sulfat masam. Menurut Eimers et al. (2003), karakteristik tanah sulfat masam ditandai dengan $\mathrm{pH}$ rendah dan potensi kemasaman yang tinggi. Nilai $\mathrm{pH}_{\mathrm{f}}$ mempunyai kisaran rata- rata 6,53 $\pm 1,27$ (kedalaman 0-20 cm) hingga 6,77 $\pm 0,20$ (kedalaman 60-80 cm).

$\mathrm{pH}_{\text {FOX }}$ berkisar antara 0,68 $\pm 0,22$ (kedalaman $60-80 \mathrm{~cm}$ ) hingga 1,04 $\pm 0,72$ (kedalaman $20-40 \mathrm{~cm}$ ). Sedangkan nilai dari selisih kedua peubah tingkat kemasaman yaitu pHF- pHFox berkisar antara 4,34 \pm 1,25 (kedalaman 60$80 \mathrm{~cm}$ ) hingga 5,03 $\pm 1,43$ (Gambar 1), dengan demikian maka tanah tambak dapat digolongkan sangat masam terutama pada kedalaman $60-80 \mathrm{~cm}$.

Konsentrasi sulfur yang berpotensi kemasaman pada tambak diduga berasosiasi dengan tanah sulfat masam dapat dikaji dari peubah $\mathrm{S}_{\mathrm{KCI}}(\%), \mathrm{S}_{\mathrm{p}}(\%), \mathrm{S}_{\mathrm{POS}}(\%)$, TPA, dan TSA. $\mathrm{S}_{\mathrm{KCl}}(\%)$ merupakan persentase sulfur yang konstan, sedangkan $\mathrm{S}_{\mathrm{p}}(\%$ menunjukkan kearah persentase total (aktual dan potensial) dari sulfur yang mempunyai potensi untuk tingkat kemasaman tanah. Sedangkan selisih antara
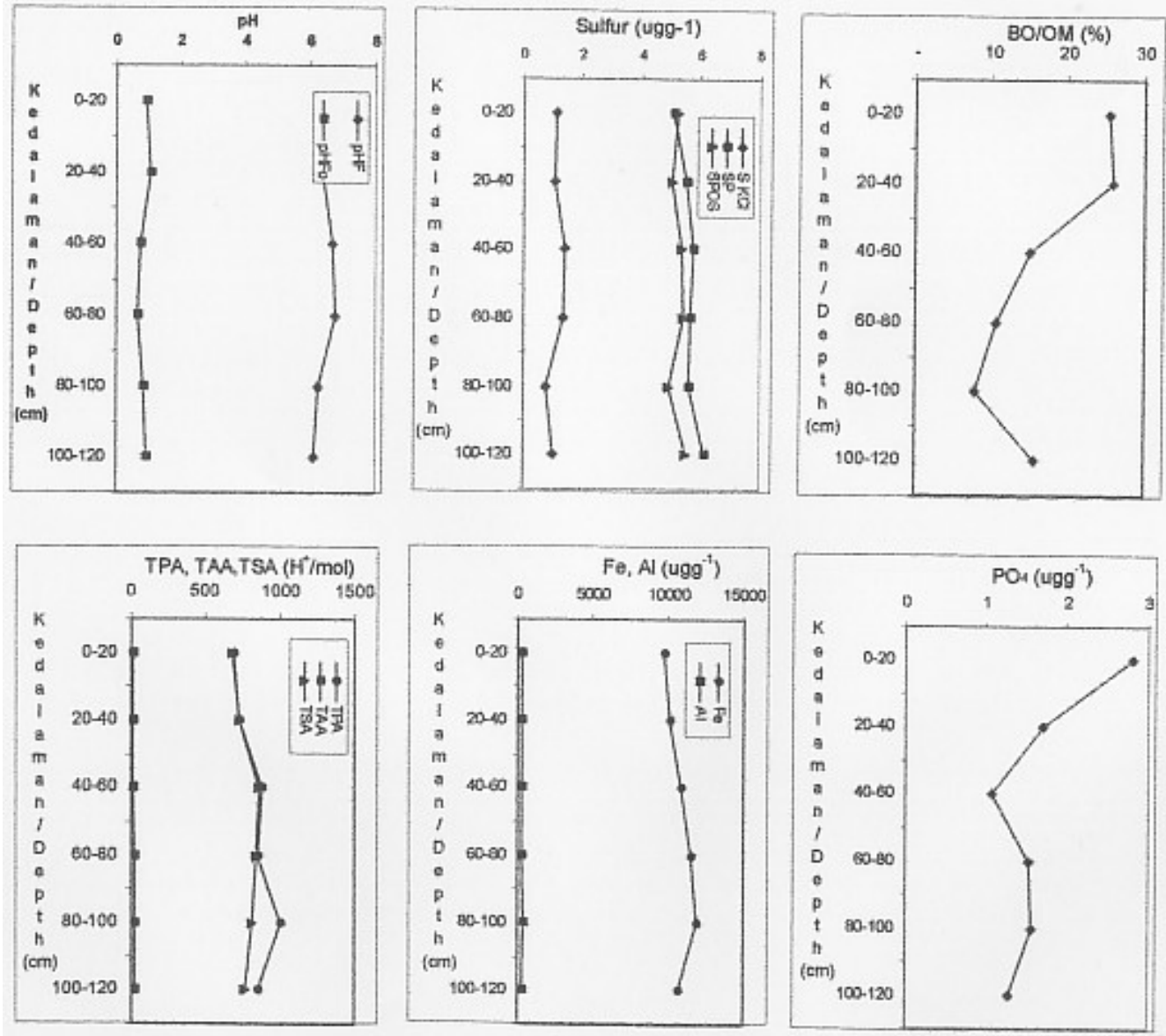

Gambar 1. Grafik kualitas tanah tambak tanah sulfat masam pada kedalaman tanah hingga $120 \mathrm{~cm}$ (setiap 20 cm), di Kecamatan Malili, Kabupaten Luwu Timur, Sulawesi Selatan

Figure 1. Graphics of soil quality in acid sulfate soil pond on soil depth until $120 \mathrm{~cm}$ (eachs of $20 \mathrm{~cm}$ ) at Malili Sub District, East Luwu Regency, South Sulawesi 
keduanya $\left(\mathrm{S}_{\mathrm{Pos}}\right)$ merupakan potensi dari kemasaman tanah dari sulfur yang tidak teroksidasi (dapat dioksidasi dengan $\mathrm{H}_{2} \mathrm{O}_{2}$ ).

Tanah yang kemasaman tinggi disebabkan oleh konsentrasi pirit yang tersebar hampir di semua daerah yang disurvai (Gambar 2). Kandungan pirit tertinggi dijumpai pada tambak baru. Konsentrasi pirit mencapai kisaran $1,24 \%-4,45 \%$ Konsentrasi pirit terendah ratarata dijumpai pada kedalaman $0-20 \mathrm{~cm}$ dan tertinggi pada kedalaman $60-80 \mathrm{~cm}$.

Tanah kaya mineral pirit yang apabila penanganannya keliru berubah menjadi tanah sulfat masam yang mengandung berbagai unsur kimia yang mencapai taraf beracun seperti sulfida, sulfat, aluminium, mangan, besi, dan berbagai senyawa organik berbahaya bagi udang (Boyd, 1995). Tanah sulfat masam dapat menjadi tanah produktif apabila unsur toksit dalam tanah tersebut dapat diredam. Namun untuk menjadikan tanah sulfat masam menjadi produktif juga memerlukan biaya yang tidak sedikit.

Meskipun nilai kualitas tanahnya bervariasi, namun karena didukung oleh sumber air yang memadai, Iahan semacam ini dapat diperbaiki menjadi lahan yang produktif bila tanahnya diremediasi dengan mereklamasi tanah, pengapuran, dan perbaikan irigasi.

Bahan organik tanah yang tinggi di kawasan ini diduga berpotensi sebagai sumber kemasaman. Kandungan bahan organik tanah

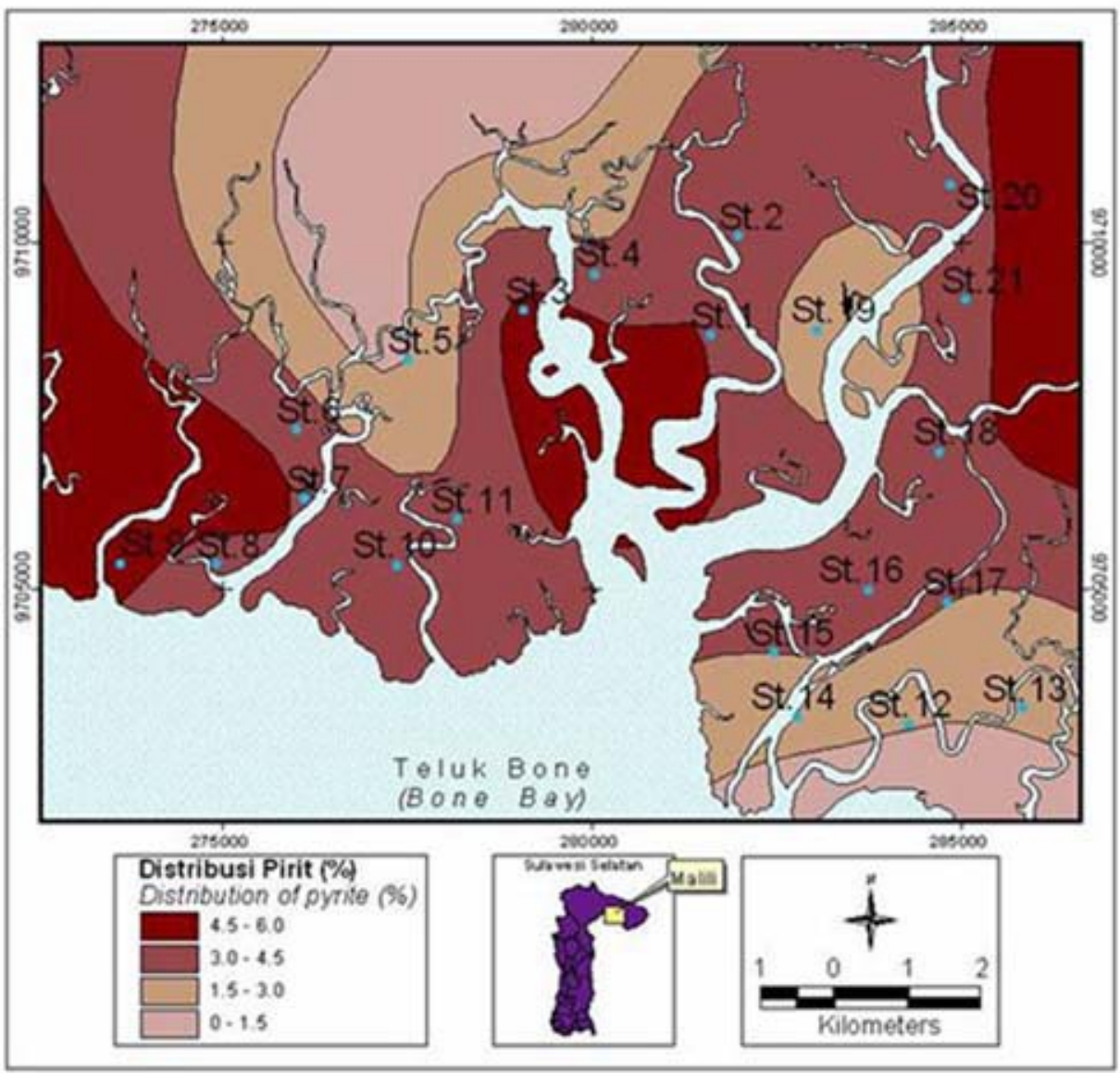

Gambar 2. Sebaran pirit pada lokasi survai di Malili Kabupaten Luwu Timur, Sulawesi Selatan

Figure 2. Distribution of pyrite of survey location at Malili, East Luwu Regency, South Sulawesi 
di daerah yang disurvai berkisar 25,26\%$33,42 \%$ Kandungan bahan organik tinggi tidak baik untuk dibuat pematang karena porositas dan subsidensi tinggi, namun tambak yang sudah lama dibangun tanahnya cukup kuat untuk dijadikan pematang tambak.

\section{Sumber Air}

Daerah yang disurvai rata- rata mempunyai sumber air yang cukup menunjang untuk kegiatan budi daya tambak karena selain lokasinya berdekatan dengan laut, juga terdapat sungai yang cukup lebar sehingga tambaknya terjangkau pasang surut air laut. Hasil pengamatan pasang surut di daerah ini terjadi perbedaan pasang surut cukup besar dengan kisaran 40-220 cm atau rata- rata $126,86 \mathrm{~cm}$. Menurut Mustafa et al. (1994), bahwa perbedaan pasang surut (pasut) di Malili pada tahun 1994 dapat mencapai $230 \mathrm{~cm}$. Tinggi permukaan air selama pasang tinggi untuk mengairi tambak di Kecamatan Malili dipengaruhi oleh frekuensi amplitudo pasang, kontur tanah dan elevasi.

Salinitas air mempunyai kisaran 7-30 ppt. Perbedaan salinitas dari sumber air pada saat pasang dan surut karena sungai- sungai yang ada disekitar tambak yang disurvai tergolong sungai hidup yang mengalirkan sumber air tawar dari hulu ke muara.

Tunggang pasut untuk daerah pertambakan menurut hasil analisis data pengukuran pasut untuk 38 jam pengukuran (Gambar 3), sebesar $104 \mathrm{~cm}$, dengan tunggang pasut terkecil menurut data pasut prediksi Dinas Hidro Oseanografi (2004), dapat dijumpai pada awal hingga akhir September.

\section{Kesesuaian Lahan untuk Tambak}

Penilaian kesesuaian lahan untuk tambak berdasarkan nilai minimum, yakni faktor pembatas yang paling menentukan dengan memperhatikan faktor lingkungan yang mendukung untuk budi daya tambak. Dari hasil analisis terhadap faktor pembatas yang ditentukan, maka dapat diestimasi potensi dan kelayakan tambak di Kecamatan Malili, Luwu Timur mencapai luas 5617,9 ha yang terdiri atas 709,4 ha kelayakan tinggi; 3947,7 ha kelayakan sedang; dan 960,7 ha kelayakan rendah. Dalam kelayakan lahan ini sudah dipertimbangkan aspek jalur hijau dalam

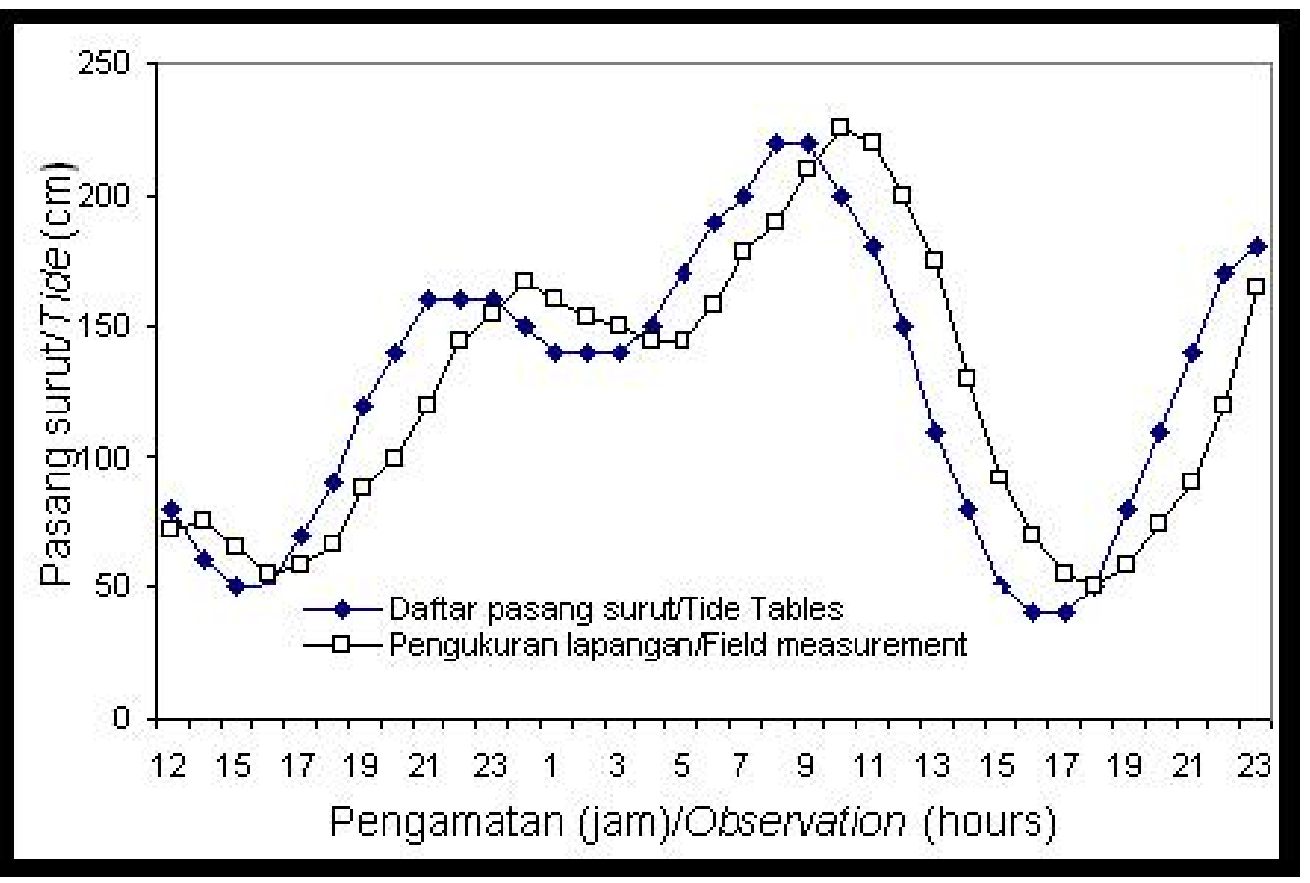

Gambar 3. Pasang surut air laut di Delta Tampina, Malili, Luwu Timur, Sulawesi Selatan

Figure 3. Tide of water sea in Tampina Delta, Malili, East Luwu, South Sulawesi 
penentuan kelayakan lahan. Lebar jalur hijau minimal $130 \times$ pasang tinggi rata- rata $( \pm 300 \mathrm{~m})$ di sepanjang pantai dan sekitar $100 \mathrm{~m}$ di sepanjang sisi sungai. Namun demikian kelayakan ini belum mempertimbangkan daerah penyangga, saluran, rumah jaga, dan lain- Iain. Dari luasan tersebut sekitar 55\%dari potensi lahan $(5.617,9$ ha) yang bisa dijadikan tambak, maka sekitar 3.089,845 ha yang bisa digunakan untuk tambak terdiri atas 390,17 ha kelayakan tinggi; 2.171,235 ha kelayakan sedang; dan 528,385 ha kelayakan rendah (Gambar 4). Meskipun tergolong kelayakan tinggi namun untuk budi daya udang disarankan menggunakan teknologi sistem tradisional plus hingga semi intensif. Hal ini disebabkan adanya senyawa pirit yang konsentrasinya bervariasi. Selain itu pada tanah sulfat masam yang berasosiasi dengan tanah bergambut di daerah ini kurang baik untuk dijadikan pematang tambak baru, karena tanahnya rapuh, berporositas dan subsidensi tinggi. Pada tingkat kelayakan sedang teknologi yang bisa digunakan adalah budi daya udang sistem tradional atau alternatif komoditas perikanan lain seperti bandeng dan

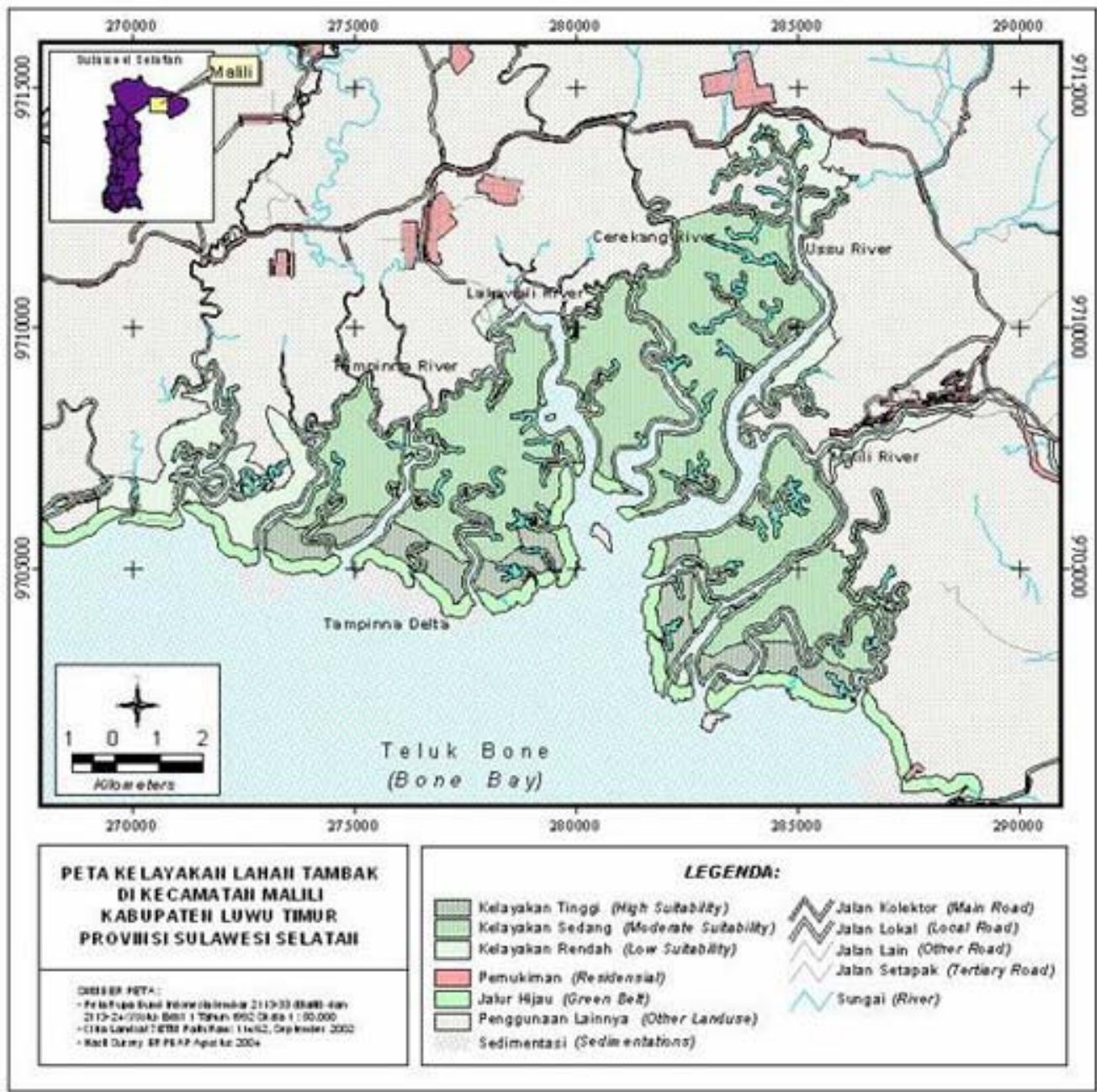

Gambar 4. Kesesuaian lahan untuk budi daya tambak di tanah sulfat masam, Malili Kab. Luwu Timur, Sulawesi Selatan

Figure 4. Suitable of area for aquaculture of acid sulfate soil, Malili, East Luwu Regency, South Sulawesi 
rumput laut yang diketahui lebih tahan pada kondisi lingkungan tambak tanah sulfat masam. Menurut Pantjara (2002), bandeng yang dipelihara di tambak tanah sulfat masam Maranak dapat mencapai sintasan sekitar 92\% demikian pula dengan rumput laut yang diketahui dapat tumbuh baik di lingkungan tambak tanah sulfat masam di daerah Lamasi Pantai, Luwu. Sedangkan kelayakan rendah berpotensi untuk pengembangan tambak terutama untuk budi daya bandeng dan rumput laut, namun masih banyak yang harus diperbaiki, terutama saluran irigasi sebagai jalan untuk mendapatkan pasok air tambak serta faktor lainnya.

\section{KESIMPULAN}

1. Hasil karakteristik lahan di Malili, Kabupaten Luwu didominansi oleh tanah sulfat masam yang umumnya berasosiasi dengan tanah gambut.

2. Berdasarkan kriteria kelayakan lahan tambak tanah sulfat masam di Malili, Luwu Timur, Sulawesi Selatan didapatkan potensi lahan pertambakan seluas $5.617,9$ ha dan yang bisa dijadikan untuk tambak sebesar 3.947,7 ha sisanya $(1.732,2$ ha) digunakan untuk daerah penyanggah, saluran, dan lain- lain. Dari luasan tambak 3.947,7 ha terdiri atas kelayakan tinggi sebesar 390,2 ha; kelayakan sedang $2.171,2$ ha; dan kelayakan rendah sebesar 528,8 ha.

3. Pada lahan dengan kelayakan tinggi masih diperlukan remediasi tanah bila untuk budi daya udang windu, sedangkan pada kelayakan sedang dan rendah disarankan untuk budi daya bandeng dan rumput laut.

4. Kawasan pertambakan daerah yang disurvai perlu tindakan untuk merehabilitasi hutan mangrove yang terlanjur rusak sebagai daerah penyangga maupun sebagai jalur hijau.

\section{DAFTAR PUSTAKA}

Anonimous. 2003. Potensi Perikanan dan Kelautan. Dinas Pertanian, Kelautan dan Perikanan Kabupaten Luwu Timur.

APHA (American Public Health Association). 1998. Standard Methods for Examination of Water and Waste-Water. 20th edition. APHA, AWWA, WEF, Washington, 1,085 pp.

Bengen, D.G. 2004․ Ekosistem dan Sumberdaya Alam Pesisir dan Laut serta Prinsip Pengelolaannya. Pusat Kajian Sumberdaya Pesisir dan Lautan. Institut
Pertanian Bogor, $72 \mathrm{pp}$.

Bengen, D.G. 2004 ${ }^{\mathrm{b}}$. Pengenalan dan Pengelolaan Ekosistem Mangrove. Pusat Kajian Sumberdaya Pesisir dan Lautan. Institut Pertanian Bogor, 59 pp.

Boran, E. and J. Hambrey. 1998. Mangrove conservation and coastal management in South East Asia: What impact on Fishery Resources? Marine Pollution Bulletin, 37 (8-12), p. 431-440.

Boyd, C.E. 1995. Bottom Soils, Sediment, and Pond Aquaculture. Chapman \& Hall. Auburn University, Alabama, 347 pp.

Duivenbooden, N.V. 1995. Land Use Systems Analysis as A Tool in Land Use Planning, $176 \mathrm{pp}$.

Eimers, M.C., P.J. Dillon, S.L. Schieff, and D.S. Jefries. 2003. The effects of drying and reweting and increased temperature on sulphate release from upland and wetland material. Soil Biology and Biochemistry, 35: 1,663-1,673.

Gunawan, I. 1998. Typical geographic information system (GIS) application for coastal resources management in Indonesia. Indonesia Journal of Coastal and Marine Resource Management, 1(1): 1-12.

McRae, S.G. and C.P. Burnham. 1981. Land Evaluation. Clanrendon Press Oxford, 239 pp.

Melville, M.D. 1993. Soil Laboratory Manual. School of Geography, University of New South Wales, Sydney, 74 pp.

Mustafa, A., A. Hanafi, B. Pantjara, dan Suwardi. 1994. Karakteristik Lahan Mangrove di Delta Tampina, Kabupaten Luwu, Sulawesi Selatan.

Nath, S.S., J.P. Balte, L.G. Ross, and J. AguilarManjarrez. 2000. Application of geographical information system (GIS) for spatial decision support in aquaculture. Aquacultural Engineering, 23: 233-278.

Neiland, A.E., N. Soley, J.B. Varley, and D.J. Whitmars. 2001. Shrimp aquaculture: economic perspectives for policy development. Marine Policy, 25: 265-279.

Pantjara, B., S. Tahe, M. Amin, dan E.H. Hendradjat. 2002. Budidaya bandeng, nila merah dan rumput laut di tambak tanah sulfat masam. Laporan Penelitian Balai Riset Perikanan Budidaya Air Payau, Maros, 21 pp.

Poernomo, A. 1992. Pemilihan Lokasi Tambak Udang Berwawasan Lingkungan. CRIFI Pub., $40 \mathrm{pp}$. 
Wisnubroto, S. 1999. Meteorologi Pertanian Indonesia. Mitra Gama Widya. Yogyakarta, $155 \mathrm{pp}$. 
Lampiran 1. Kriteria kelayakan lahan untuk budi daya tambak udang Appendix 1. Criteria of land suitability for shrimp brackis water pond culture

\begin{tabular}{|c|c|c|c|c|}
\hline Parameter & Kisaran (Range) & $\begin{array}{l}\text { Bobot } \\
\text { Weigh }\end{array}$ & $\begin{array}{l}\text { Skor } \\
\text { Score }\end{array}$ & $\begin{array}{l}\text { Nilai } \\
\text { Value }\end{array}$ \\
\hline $\mathrm{pH}$ tanah (Soil) pH & $\begin{array}{l}6.5-8.0 \\
5.0-6.5 \\
<5.0 \&>8.0\end{array}$ & 15 & $\begin{array}{l}3 \\
2 \\
1\end{array}$ & $\begin{array}{l}45 \\
30 \\
15\end{array}$ \\
\hline Lereng (Slopes) $(\%$ & $\begin{array}{l}0-2 \\
2-4 \\
>4\end{array}$ & 15 & $\begin{array}{l}3 \\
2 \\
1\end{array}$ & $\begin{array}{l}45 \\
30 \\
15\end{array}$ \\
\hline Tekstur (Texture) & $\begin{array}{l}\text { Lempung liat berpasir, liat berdebu, } \\
\text { lempung berpasir } \\
\text { Lempung, lempung berdebu, liat } \\
\text { berdebu, liat berpasir } \\
\text { Liat, pasir, bergambut, kandungan } \\
\text { pirit tinggi }\end{array}$ & 15 & $\begin{array}{l}3 \\
2 \\
1\end{array}$ & $\begin{array}{l}45 \\
30 \\
15\end{array}$ \\
\hline $\begin{array}{l}\text { Iklim(curah hujan) } \\
\text { Climate (rainfall) }\end{array}$ & $\begin{array}{l}2,000-2,500 \mathrm{~mm} / \text { tahun } \\
1,000-2,000 \mathrm{~mm} / \text { tahun } \\
<1,000 \&>2,500 \mathrm{~mm} / \text { tahun }\end{array}$ & 10 & $\begin{array}{l}3 \\
2 \\
1\end{array}$ & $\begin{array}{l}30 \\
20 \\
10\end{array}$ \\
\hline Jarak dari garis pantai (m) & $\begin{array}{l}300-1,000 \\
1,000-3,000 \\
>3,000\end{array}$ & 10 & $\begin{array}{l}3 \\
2 \\
1\end{array}$ & $\begin{array}{l}30 \\
20 \\
10\end{array}$ \\
\hline Tipe garis pantai & $\begin{array}{l}\text { Konsistensi tanah stabil } \\
\text { Konsistensi sedang-labil } \\
\text { Konsistensi tanah labil-sangat labil }\end{array}$ & 10 & $\begin{array}{l}3 \\
2 \\
1\end{array}$ & $\begin{array}{l}30 \\
20 \\
10\end{array}$ \\
\hline $\begin{array}{l}\text { Penutup lahan } \\
\text { Landcover }\end{array}$ & $\begin{array}{l}\text { Lahan kosong, belukar, tegalan } \\
\text { Sawah, kebun } \\
\text { Mangrove, rawa }\end{array}$ & 10 & $\begin{array}{l}3 \\
2 \\
1\end{array}$ & $\begin{array}{l}30 \\
20 \\
10\end{array}$ \\
\hline Keterjangkauan & $\begin{array}{l}\text { Lancar } \\
\text { Cukup lancar } \\
\text { Tidak lancar }\end{array}$ & 5 & $\begin{array}{l}3 \\
2 \\
1\end{array}$ & $\begin{array}{c}15 \\
10 \\
5\end{array}$ \\
\hline Tenaga kerja & $\begin{array}{l}\text { Banyak } \\
\text { Cukup tersedia } \\
\text { Tidak tersedia }\end{array}$ & 4 & $\begin{array}{l}3 \\
2 \\
1\end{array}$ & $\begin{array}{c}12 \\
8 \\
4\end{array}$ \\
\hline Keamanan & $\begin{array}{l}\text { Aman } \\
\text { Cukup aman } \\
\text { Tidak aman }\end{array}$ & 3 & $\begin{array}{l}3 \\
2 \\
1\end{array}$ & $\begin{array}{l}9 \\
6 \\
3\end{array}$ \\
\hline Pemasaran & $\begin{array}{l}\text { Lancar } \\
\text { Cukup lancar } \\
\text { Tidak lancar }\end{array}$ & 3 & $\begin{array}{l}3 \\
2 \\
1\end{array}$ & $\begin{array}{l}9 \\
6 \\
3\end{array}$ \\
\hline Jumlah & & 100 & & \\
\hline
\end{tabular}

